\title{
Liberal Arts Education: The Essential Foundation for Vocational Education
}

\author{
Yihui Yu \\ Wuhan Railway Vocational College of Technology \\ Wuhan, China
}

\begin{abstract}
While unable to bring direct economic benefit, liberal arts education provides our students much needed value system and guidance in their growth. It must be pointed out that nobody is born with humanistic aptitude, which must be acquired through quality education. Although the purpose of vocational education is to provide professionals with practical skills to the society, overemphasis on the education of skills and neglect of liberal arts education will lead to serious consequence to students' overall development. This paper argues that in vocational education we should strive to cultivate our students to become a well-rounded person with healthy personality, excellent professional capacity, and ability to deal with the challenge in real world.
\end{abstract}

Keywords-liberal arts education; vocational education; purpose of education; positioning

\section{INTRODUCTION}

In "Recent Advices on Reforming Vocational Education from the Ministry of Education", it is made very clear that to cultivate students' morality and help their overall development should be the basic principle of our vocational education. In practice, the advices emphasizes that we should follow the rule of vocational education, as well as the rule of students' physical and psychological development. Ultimately, to increase the quality of the students, we should focus on morality, humanistic aptitude and professional capacity.[1] This document demonstrates an important idea in education, that is, we must take students as the center of our education, and we must care about the overall and sustainable development. It is true that the purpose of vocational education is to educate our students to be professionals with practical skills. But we must be aware that, it is impossible for students' continuous development and physical and psychological health if we put too much emphasis on technical skills and neglect the cultivation of students' personality.

\section{The StRATEgIC SignificANCE OF LiBERAL ARTS EDUCATION}

Citizens' competence is an important index for a nation's development level, which is ultimately decided by the quality of its liberal arts education. Aiming to cultivate an ideal personality, with an emphasis on the reflection of the goal of life, the importance of liberal arts education lies in not just its influence on the overall aptitudes of the students, but also its effects on shaping the spirit of a nation. As Lu Xun said about one hundred years ago: "the most important thing for state affairs is people. Once we have the right people, right thing will be easy to be done." [2]We can see this understanding in today's world as well, as the governments of many countries attempt to improve the overall competence of their citizens through education.

In 21st century, due to the concern about the national interest and continuous development, the governments of many countries have made the cultivation of their citizen's overall aptitude as the goal of their general educational plan. Take Australia as an example, the plan of their new century education put much emphasis on knowledge and competence, on the understanding of culture, and the capacity for further individual development. Specifically speaking, the first goal of their educational plan is the development of all students' intelligence and competence, including the ability of critical thinking and problem solving, the ability of interpersonal communication. Meanwhile, the educated are also expected to be a confident, optimistic, and dignified member of the society, with self-deciding capacity, social responsibility, and sound value; with healthy attitudes towards society, life, environment, and profession; ultimately become a patriotic citizen. The third goal of Australia's overall education plan is about the justice of education, including helping students understand and respect the linguistic and cultural diversity and with the capacity to promote this diversity.[3] In a nutshell, the goal of this education plan is for the overall and balanced development of the educated. The concern of this plan is not only the professional skills of the educated, but also the ability of the educated to deal with people, the society, and the environment, as well as their ability to further develop themselves. What we might call an overall aptitude and continuous development capacity. While all these competence must be based on a well-developed liberal arts education, without which many of the above mentioned goals just could not be materialized.

It must be pointed out that the above mentioned plan is designed for what we would call "big education", including elementary education, secondary education, higher education, as well as vocational education-both middle-level (i.e., after middle school) and higher level (i.e., after high school). In essence, this plan expects that long term sustainable development of the nation must be based on the continuous increase of its citizens' overall aptitude. In other words, the quality of education not only affects individual, but also the nation as a whole. 


\section{LACK OF LIBERAL ARTS EDUCATION WILL ULTIMATELY COMPROMISE THE GOAL OF EDUCATION}

American Philosopher John Dewey once said, education is first about human, and then about profession. Since the 20th century, we have been paying more and more attention to professional education, which on the one hand satisfied the need of the development of science and technology, on the other hand, somehow restricted the vision of the students. In other words, the pragmatism has become a more and more obvious trend in education. In this context, especially in facing the challenge brought by the contradiction of modern society, in order to alleviate the negative influence on the growth of the younger generation caused by the overemphasis of professional education, some developed countries have begun to pay more attention to liberal arts education, i.e., to emphasize on the aptitude and competence of students, particularly students' ability to adjust to the society, ability in oral and written communication, and the ability to understand different cultures. In this way, education will be able to help students get rid of the narrow mindedness resulted from the overemphasis on professional education and get broader vision and understanding. From a UNESCO document issued in 1996 entitled "LEARNING, THE TREASURE WITHIN", we can find an alternative understanding of liberal arts education. This document proposes the idea of four foundations of education: learn to know, learn to do, learn to cooperate, and learn to survive.[4] The four "learns" help the development of our students become moral and responsible citizens with broad knowledge, critical thinking ability, problem-solving capacity, and social consciousness, which is extremely important for us to solve the basic problems that our modern society is facing. This document reminds us again that the acquisition of professional skills is not the ultimate goal of education. A sound education should pay attention to both the knowledge and skills that are necessary for career development and the cultivation of humanistic aptitude to ensure the students a life with quality and become competent citizen.

Vocational education, regardless of its own features, cannot be deviated from this ultimate goal of education. In vocational education, we must put the emphasis on cultivation of the basic aptitude of our students, which must be the fundamental principle for us, just like in any other kinds of education. In 2001, UNESCO made the following suggestions for vocational education in a document entitled "revised suggestions to technological and vocational education", in which the following four aspects are highly emphasized: 1.the harmonious development of personality and character, appropriate value system, and ability in understanding, judgement, analysis, and communication. 2. Ability of life learning, which we should help them acquire through an education that focuses on method and attitudes. 3. Ability in making an argument, cooperation and leadership. 4. Ability to deal with the rapidly digitalized society. As we can see the huge gap between this ideal situation for vocational education and reality. The pursue for utility without any restrain in vocational education could make our students "machine" rather than human being. Liang Sicheng has called this kind of education as the education for "half man", and argued vigorously to step out of the era of "half man", which we still need to set as the goal for education in our time.

\section{GET RID OF OVEREMPHASIS ON UTILITY IN VOCATIONAL EDUCATION}

The loss of liberal arts education resulted from the pervasive pragmatism in vocational education as well as in the society at large. The pursue of actual benefit in society, the obsession with children's concrete “achievement” among parents, and the focus on the job placement in our schools, all these are factors that could decrease our attention to liberal arts education. To produce students with practical and useful skills almost become the only goal for many schools. The overemphasis on technology and skills could lead to the neglect of the spiritual world of our students, ignoring the importance of cultivating students' personality and morality. In reality, we can see that on the one hand, some school administrators and faculty members believe that it is the "concrete" skills, not the useless humanity courses that can give students the chance to get a "good" job, thus is the foundation of their future career and life; on the other hand, many students share the same belief, making "usefulness" as the most important criterion in their course selection even in their decision whether or not to take part in a certain extra-curriculum activity. In this context, the "useless" humanity courses and related activities are always neglected, which has become the most serious crisis liberal arts education is facing in vocational colleges.

\section{What Is The Exact Role Of LiBeral ARTS EduCAtion IN VOCATIONAL COLLEGES}

\section{A. The purpose of liberal arts education in vocational colleges is to provide general education}

The concept of general education appeared first in United States in early 19th century. In General Education in a free Society, the famous "red book" by Harvard University, a central point is that a real freeman must be able to be responsible to himself/herself, with the capacity of self-judgement, self-reflection, and self-improvement.[6] Different from the focus on professional knowledge and professional skills in disciplinary training, general education focus on the diffusion of knowledge in humanities and sciences, the inheritance of the legacy of civilizations, and the cultivation of personality. It is undeniable that this kind of education is essentially significant for the development of students' knowledge structure, aesthetic ability, creativity and overall growth. In other words, general education is not about the preparation of the knowledge or skills you need for future career, but help you become a person with good personality and character, which will ultimately help you succeed in your career and in the society. Regardless of difference in profession, all citizens should have correct way of thinking and a sense of social responsibility. For our students' future continuous growth, they need a comprehensive education to help them build a solid foundation, which is not something they can get from a narrowly defined professional education which only focus on knowledge and skills in specific discipline. 
So it must be clear that the purpose of liberal arts education in vocational schools is not to train future experts in certain discipline, but to improve the general aptitude of our students. It is not disciplinary education, not professional education, but general education. Consequently, that means all students of vocational schools must receive liberal arts education; the schools must design a well-structured liberal arts curriculum and related extra-curriculum activities; faculty need to choose appropriate textbooks and use appropriate teaching methods to achieve the best result; and finally faculty in every discipline shall be aware of the mission of liberal arts education, incorporating liberal arts education into their classroom teaching.

\section{B. Liberal Arts Education in Vocational Colleges must be strengthened}

Narrowly defined vocational education, focusing on the training of skills, will at most provide students with technical skills required for a certain job, somehow a useful machine rather than a well-developed person, which is ultimately relied on liberal arts education. Only through the diffusion of knowledge, culture, belief, and value in our liberal arts education that we can reshape our students' personality and characters. Receiving a liberal arts education, our students will learn how to deal with interpersonal relation, the relation between human being and environment, and the relation between individual and society; they will also learn self-management; most importantly, they will gradually acquire humanistic spirit; with the capacity of self-reflection, they will be able to think about the meaning of life. So liberal arts education is absolutely not unnecessary in our vocational education, on the contrary, liberal arts education must be strengthened.

\section{1) Human is the foundation of education in vocational} colleges

We must realize that the purpose of vocational education is not to produce machine. To cultivate well developed person, in our education, we must start with developing the potential of students and focus on the improvement of students' overall competence. We should make a democratic, harmonious, and ordered classroom environment through multiple approaches, so our students could be immersed in the atmosphere of humanism, gradually building up their own humanistic spirit and aptitude, ultimately become a well -developed person.

2) We must abandon pragmatism in vocational colleges

In our curriculum, there must be a place for humanity courses, including literature, history, philosophy, psychology, and law, etc. introducing the rich legacy of human civilization to our students. Consequently, students will have more opportunities and channels to access the knowledge related to society and culture.

3) Combining liberal arts education with professional education

We must pay attention to the combination of humanistic cultivation and professional education. Our job is not to provide mere craftsman to the society but the spirit of craftsman. In essence, to fulfill the goal of liberal arts education is the obligation of every faculty, regardless of discipline. The history of human being is a process of exploration, discovery, innovation, and invention. None of these events are simply a matter of technology, they are all closely related to other facets of human society and culture. I believe that is where our faculty in technology courses can incorporate humanistic spirit into their classroom teaching.

\section{CONCLUSION}

1. We must realize that humanistic aptitude is not something we can get naturally, like all knowledge and capacities; it must be acquired through study.

2. Even though liberal arts education cannot bring direct economic benefit, but it can provide appropriate value system and life guidance that are essential important to students' growth.

3. Humanistic aptitude and professional skills are the two wings for our students' success. Liberal arts education and professional education are not exclusive, but complementary. Lacking either part will compromise the goal of our education. So in vocational colleges' curriculum, there must be a place for humanity courses, introducing the rich legacy of human civilization to our students.

4. We should make a democratic, harmonious, and ordered classroom environment through multiple approaches, so our students could be immersed in the atmosphere of humanism, gradually building up their own humanistic spirit and aptitude; ultimately become a well -developed person. As Einstein said, we must ensure that upon graduation, our students must be a well-developed person, not just an expert. In other words, the mission of vocational colleges is to make our students become a well-rounded person with healthy personality and characters, excellent professional skills who can confidently deal with all the challenges in their life and career.

\section{REFERENCES}

[1] Ministry of Education of the People's Republic of China, Some opinions on deepening the reform of vocational education and teaching and comprehensively improving the quality of personnel training. (In Chinese)

[EB/OL].http://www.moe.edu.cn/srcsite/A07/moe_953/moe_958/20150 8/t20150817_200583.html

[2] Luxun, The theory of cultural bias Henan, August 1908. (In Chinese)

[3] UNESCO,Learning, the treasure within, Beijing, Educational Science Press, 1996

[4] Daming Feng, Jingzhong Zhao, A review of national education strategies of Britain, the United States and Australia in the early 21st century, Educational development research2002 (10) PP.32-36. (In Chinese)

[5] UNESCO, Revised suggestions to technological and vocational education,[EB/OL].http://unesdoc.unesco.org/images/0012/001246/1246 87c.pdf (In Chinese)

[6] Lizhu Pan, Introduction to general education in a free society. [EB/OL].http://www.doc88.com/p-099398574339.html (In Chinese) 